\title{
KAJIAN PENGETAHUAN VULVA HYGIENE TERHADAP PERAWATAN PERINEUM DI KLINIK SUKO ASIH SUKOHARJO
}

\author{
Vulva Hygiene Knowledge Assessment Of Perineum Care \\ In Suko Asian Sukoharjo Clinic \\ Wahyuni ${ }^{1}$ All fraida adi pratama ${ }^{2}$ \\ Sekolah Tinggi Ilmu Kesehatan 'Aisyiyah Surakarta \\ (yunyskh@gmail.com)
}

\begin{abstract}
ABSTRAK
Latar belakang : melahirkan seorang anak memang menjadi kebahagiaan tersendiri bagi seorang wanita, Perawatan perineum pada wanita sehabis melahirkan merupakan suatu perilaku yang harus dilakukan. tetapi tidak dipungkiri perineum akan mengalami perlukaan saat proses persalinan. Untuk itu dibutuhkan masa untuk pemulihan yang disebut masa nifas dan selama masa tersebut seorang ibu harus benar-benar menjaga kebersihan terutama perineum untuk menghindari komplikasi yang terjadi setelah melahirkan.

Tujuan : mengetahui perilaku perawatan perineum berkaitan pengetahuan ibu nifas mengenai vulva hygiene

Metode : rancangan dalam penelian ini merupakan penelitian analitik dengan pendekatan cross sectional. Responden penelitian ibu nifas yang melahirkan sebanyak 80 orang teknik sampling menggunakan purposive sampling jumlah sampel total populasi. Analisa yang digunakan dalam analisa bivariat korelasi Kendal tau.

Hasil : Terdapat hubungan antara pengetahuan dengan perilaku perawatan perineum dengan nilai $\rho_{\text {value }}<0.001$.

Kesimpulan : Ada hubungan antara pengetahuan ibu nifas tentang vulva hygiene dengan perilaku perawatan perineum.
\end{abstract}

Kata Kunci : Ibu Nifas; Perawatan Perineum; Pengetauan

\begin{abstract}
ABSTRAC
Background: Treatment of perineum in women after childbirth is a behavior that must be done. giving birth to a child is truly a happiness for a woman, but it is undeniable that the perineum will experience injury during labor. For this reason, a recovery period called the puerperium is needed and during that period a mother must really maintain cleanliness, especially the perineum, to avoid complications that occur after giving birth.

Objective: to determine the behavior of perineal care with postpartum knowledge about vulva hygiene

Method: the design in this study was an analytical study with a cross sectional approach. The respondents of the postpartum mothers who gave birth were 80 people. The sampling technique used purposive sampling, the total sample
\end{abstract}


population. The analysis used in the bivariate analysis of the Kendal tau correlation.

Results: There is a relationship between knowledge and perineal care behavior with a value of $<0.001$.

Conclusion: There is a relationship between postpartum mother's knowledge about vulva hygiene and perineal care behavior.

Keywords: Mother Nifas; Care of the Perineum; Knowledge,

\section{PENDAHULUAN}

Kehadiran seorang anak di dalam keluarga memang menjadi anugerah yang paling dinanti oleh setiap pasangan yang baru menikah, karena mereka merasa dengan kehadiran sang anak akan memberikan kehidupan yang lebih. Kehamilan dan melahirkan seorang anak memang menjadi kebahagiaan tersendiri bagi seorang wanita, terlebih pada wanita yang baru melahirkan bayi pertama, dimana ia juga baru pertama kalinya menjalani kehidupan dan memiliki tanggung jawab lebih dari sebelumnya ketika belum memiliki anak. Ibu melahirkan bisa dipastikan mengalami perlukaan pada jalan lahir dimana akan mengalami pendarahan karena robeknya perineum. Robekan perineum hampir terjadi pada kelahiran pertama dan tidak menutup kemungkinan terjadi pada kelahiran berikutnya (Icesmi \& Margareth, 2013).

Profil Kesehatan Provinsi Jawa Tengah (2015) menjelaskan bahwa pelayanan kesehatan ibu nifas adalah pelayanan kesehatan sesuai standard pada ibu mulai 6 jam sampai 42 hari pasca persalinan oleh tenaga kesehatan. Jumlah cakupan ibu nifas dalam 3 tahun terakhir cenderung meningkat tetapi tidak terlalu signifikan. Tahun 2013 sebanyak 94,06\%, tahun 2014 sebanyak 95,16\%, tahun 2015 sebanyak $95,69 \%$.

Dinas Kesehatan Kota Sukoharjo (2016) bagian Kesehatan Keluarga menyatakan jumlah ibu bersalin di Kabupaten Sukoharjo sebanyak 12.622 persalinan dengan ditolong oleh tenaga kesehatan. Jumlah ini kurang memenuhi dari sasaran ibu bersalin sebanyak 13.132. Jumlah persalinan terendah terjadi di Puskesmas Bulu sedangkan tingkat persalinan 3 tertinggi terjadi di Puskesmas Kartasura (1842 persalinan), Puskesmas Grogol (1767 persalinan) dan Puskesmas Mojolaban (1353 persalinan). Dari data tersebut diketahui wilayah Puskesmas Mojolaban menduduki peringkat 3 teratas untuk jumlah ibu bersalin. Ibu nifas sangat rentan terhadap kejadian infeksi, maka dari itu sangat penting untuk ibu dalam menjaga kebersihan seluruh tubuhnya, pakaian yang digunakan dan kebersihan lingkungan. Anjuran menjaga kebersihan bagi ibu nifas salah satunya yaitu dengan

membersihkan daerah kelamin dengan sabun dan air setiap kali selesai BAK/BAB. Cara membersihkan alat kelamin di mulai dari daerah sekitar vulva dari depan ke belakang baru kemudian membersihkan daerah sekitar anus (Saleha, 2009).

Tenaga kesehatan memiliki peran cukup penting untuk memantau proses pemulihan karena pelaksanaan yang kurang baik dapat menimbulkan berbagai 
masalah pada ibu bahkan dapat berlanjut pada komplikasi masa nifas seperti sepsis dan puerperalis. Masalah yang timbul pada ibu juga akan berdampak pada kesejahteraan bayi karena bayi kurang mendapat perawatan yang maksimal dari ibu. Dengan demikian angka morbiditas dan mortalitas bayi akan semakin meningkat (Sulistyawati, 2009 dalam Satukhilmiyah, 2003).

Berdasarkan hasil studi pendahuluan didapatkan data jumlah ibu bersalin pada bulan Januari-Agustus 2017 sebanyak 401 orang dengan persalinan normal. Berdasarkan hasil wawancara pada 10 ibu post partum di klinik tersebut, 5 orang belum mengerti tentang perawatan perineum, 3 orang sudah melakukan kebersihan vulva tetapi hanya dengan sepengetahuan ibu saja dan melakukan perawatan kurang sesuai dengan yang seharusnya, 2 ibu sudah melakukan perawatan vulva hygiene dengan benar.

Berdasarkan uraian latar belakang di atas maka dapat diambil suatu rumusan masalah yaitu "apakah ada hubungan pengetahuan ibu nifas tentang vulva hygiene dengan perilaku perawatan perineum sedangkan

Kajian penelitian ini untuk memaparkan hubungan perilaku perawatan perineum ibu nifas terhadap vulva hygiene

\section{METODE PENELITIAN}

Penelitian ini adalah penelitian analitik dengan rancangan crosssectional Variabel dependen pengetahuan dan variabel independen perilaku perawatan perineum. Populasi adalah seluruh ibu nifas bulan Januari-agustus 2017 yang berjumlah 401 orang. Sampel dalam penelitian 80 responden dengan menggunakan teknik sampling purposive sampling. Instrumen untuk pengumpulan data yaitu kuesioner. Pertanyaan secara tertutup tentang pengetahuan dan perilaku. Analisa data yang digunakan adalah univariate dan bivariate. Analisa univariat dengan menghitung distribusi frekuensi dan presentase dari tiap variabel. Variabel yang dianalisis secara univariat dalam penelitian ini adalah pengetahuan dan perilaku perawatan. Analisis bivariat ini dilakukan untuk melihat hubungan antara dua variable yaitu variabel independent (bebas) dan variabel dependent (terikat).

\section{HASIL DAN PEMBAHASAN}

1. Distribusi Tingkat Pengetahuan Tentang Vulva Hygiene

Tabel 1. Distribusi Tingkat Pengetahuan Ibu Nifas di Klinik Utama Suko Asih Kabupaten Sukoharjo Pada Bulan Agustus 2017

\begin{tabular}{cccc}
\hline No & Tingkat Pengetahuan Ibu & $\mathrm{f}$ & $\%$ \\
\hline 1 & Kurang & 18 & 22.5 \\
2 & Cukup & 43 & 53.8 \\
3 & Baik & 19 & 23.8 \\
\hline & Total & 80 & 100
\end{tabular}

Sumber : data primer, 2017 
Berdasarkan Tabel 1 dapat diketahui bahwa distribusi frekuensi untuk pengetahuan ibu nifas tertinggi adalah cukup dengan jumlah responden 43 $(53.8 \%)$.

2. Distribusi Perilaku Perawatan Perineum

Tabel 2. Distribusi Perilaku Perawatan Perineum di Klinik Utama Suko Asih Kabupaten Sukoharjo Pada Bulan Agustus 2017

\begin{tabular}{cccc}
\hline No & Perilaku & $\mathrm{f}$ & $\%$ \\
\hline 1 & Kurang & 6 & 7.5 \\
2 & Cukup & 62 & 77.5 \\
3 & Baik & 12 & 15.0 \\
\hline & Total & 80 & 100
\end{tabular}

Sumber : data primer, 2017

Berdasarkan Tabel 2 dapat diketahui bahwa distribusi frekuensi terbesar perilaku ibu nifas dalam merawat perineum adalah cukup dengan jumlah responden $62(77.5 \%)$

3. Analisis Hubungan Pengetahuan Ibu Nifas Tentang Vulva Hygiene Dengan Perilaku Perawatan Perineum

Table 3. Analisis Hubungan Pengetahuan Ibu Nifas Tentang Vulva Hygiene Dengan Perilaku Perawatan Perineum di Klinik Utama Suko Asih

\begin{tabular}{|c|c|c|c|c|c|c|c|c|c|}
\hline \multirow{3}{*}{$\begin{array}{l}\text { Pengetahuan } \\
\text { ibu nifas }\end{array}$} & \multicolumn{6}{|c|}{ Perilaku perawatan perineum } & \multirow{2}{*}{\multicolumn{2}{|c|}{ total }} & \multirow[t]{2}{*}{$\rho$} \\
\hline & \multicolumn{2}{|c|}{ kurang } & \multicolumn{2}{|c|}{ Cukup } & \multicolumn{2}{|c|}{ Baik } & & & \\
\hline & $\mathrm{f}$ & $\%$ & $f$ & $\%$ & $\mathrm{f}$ & $\%$ & $f$ & $\%$ & \\
\hline Kurang & 6 & 33.3 & 12 & 66,7 & 0 & 0 & 18 & 100.0 & \\
\hline Cukup & 0 & 0 & 43 & 100.0 & 0 & 0 & 43 & 100.0 &.$<0.001$ \\
\hline Baik & 0 & 0 & 7 & 36.8 & 12 & 63.2 & 19 & 100.0 & \\
\hline Total & 6 & 7.5 & 62 & 77.5 & 12 & 15.0 & 80 & 100.0 & \\
\hline
\end{tabular}

Berdasarkan tabel 3 dapat ditarik kesimpulan bahwa ibu yang mempunyai pengetahuan baik mempunyai perilaku baik untuk merawaperineum perineum.

Hasil analisa statistic menggunakan teknik korelasi Kendal Tau didapatkan hasil $p_{\text {value }} 0.001<0,05$ sehingga $\mathrm{H}_{\mathrm{o}}$ ditolak dan $\mathrm{H}_{\mathrm{a}}$ diterima. Hal ini berarti terdapat hubungan antara pengetahuan ibu nifas tentang vulva hygiene dengan perilaku perawatan perineum di Klinik Utama Suko Asih Kabupaten Sukoharjo. 
1. Pengetahuan Ibu Tentang Vulva Hygiene di Klinik Utama Suko Asih Kabupaten Sukoharjo

Hasil penelitian menunjukkan bahwa pengetahuan ibu nifas sebagian besar adalah cukup dengan presentase $53.8 \%$ dan sedikit yang pengetahuannya kurang dengan presentase $22,5 \%$.

Faktor-faktor yang mempengaruhi Pengetahuan seseorang diantaranya faktor pendidikan, usia, pekerjaan dan lingkungan. Berdasarkan pengalaman bahwa perilaku yang didasari oleh pengetahuan akan lebih langgeng daripada yang tidak didasari oleh pengetahuan. ANC (Ante Natal Care ) merupakan cara yang baik Untuk meningkatkan pengetahuan ibu nifasibu hamil diharapkan memeriksakan kehamilan sesuai dengan pedoman selama kehamilan minimal 4 kali untuk periksa kehamilan. Atau rutin setiap satu bulan sekali hingga usia kehamilan 6 bulan, dua kali pada usia 7-8 bulan dan ketika usia kandungan 9 bulan seminggu sekali. Pasa Saat memeriksakan kehamilan bidan akan melakukan $5 \mathrm{~T}$ yaitu selain di timbang berat badan, Periksa tekanan darah dan periksa TFU ( Tinggi Fundus Uteri), penyuluhan misalnya pentingnya gizi ibu hamil, pentingnya personal hygiene, cara merawat bayi, tentang ASI eksklusif, cara merawat puting susu, cara merawat luka perineum, dan lainnya yang berhubungan dengan langkah selanjutnya yang akan dihadapi ibu untuk merawat diri dan bayinya secara optimal.

Sejalan dengan penelitian Hastuti (2013) yang menyatakan bahwa tingginya pengetahuan ibu nifas dalam proses penyembuhan luka akan mendukung mereka untuk bisa merawat luka perineum dengan baik. Hal ini diperkuat oleh adanya responden yang memiliki pengetahuan tinggi mengalami penyembuhan luka yang tidak normal (63.6\%) tetapi responden dengan pengetahuan kurang dapat mengalami proses penyembuhan normal (36\%) hal ini bisa juga deikarenakan lokasi tempat tinggal responden dekat dengan petugas kesehatan sehingga memudahkan mendapat akses pengobatan. Sedangkan responden dengan pengobatan baik tetapi memiliki proses penyembuhan yang tidak normal dapat terjadi karena kurangnya personal hygiene serta kurang memperhatikan daerah perineum dan merawat luka dengan benar.

2. Perilaku Perawatan Perineum

Hasil penelitian menunjukkan bahwa perilaku ibu nifas dalam merawat perineum adalah cukup. Perilaku merupakan kegiatan atau aktivitas makhluk hidup yang bersangkutan. Penelitian ini didukung oleh penelitian Prety V. Ett all (2017) yang menyatakan bahwa Ada hubungan antara perawatan luka perineum dengan perilaku personal hygiene ibu post partum di Rumah Sakit Pancaran Kasih GMIM,

Ibu post partum perlu memperhatikan beberapa kebutuhan dasar saat nifas salah satunya adalah perawatan perineum. Perawatan perineum menrupakan pemenuhan kebutuhan untuk menyehatkan daerah antara paha yang dibatasi oleh vulva dan anus. Perawatan perineum berfungsi untuk mencegah infeksi pada ibu nifas terkait dengan pengeluaran cairan atau lochea pada jalan lahir bayi, untuk itu sangat disarankan untuk ibu nifas melakukan perawatan secara benar agar tidak terjadi komplikasi pasca 
persalinan. Melalui pengalaman di masa lalu seseorang dapat belajar cara merawat diri. Apabila ibu sudah mengenal manfaat perawatan diri atau tehnik yang akan dilakukan, maka ibu akan lebih mudah dalam melakukan perawatan diri pascasalin. Pengalaman menjadi salah satu faktor penting dalam membentuk perilaku seseorang, dengan pengalaman yang lebih maka seseorang akan lebih juga dalam memahami yang pada akhirnya akan lebih baik juga dalam menyikapi maupun berperilaku dalam semua tindakannya (Azwar, 2010). Dalam hal ini pengalaman memberikan pengaruh pada perilaku ibu untuk melakukan perawatan diri pascasalin.

3. Hubungan Pengetahuan Ibu Nifas Tentang Vulva Hygiene Dengan Perilaku Perawatan Perineum

Pengetahuan ibu nifas tentang vulva hygiene terhadap perilaku perawatan perineum pada tabel 3 menunjukkan bahwa mayoritas responden dengan pengetahuan cukup memiliki perilaku cukup pula dalam perawatan perineum. Dengan analisa bivariat Kendal Tau menunjukkan bahwa ada hubungan antara pengetahuan ibu nifas tentang vulva hygiene dengan perilaku perawatan perineum. Hal ini sesuai dengan penelitian Ratih,R.H (2018) tingkat pengetahuan ibu nifas berubungan dengan perawatan luka perineum, juga sejalan dengan penelitiannya Maidartati (2016) bahwa ada hubungan antara pengetahuan dengan perilaku vulva hygiene

Mayoritas ibu bersalin dengan pendidikan SMA dan jumlah kelahiran kedua menjadikan masih kurangnya informasi tentang perawatan yang benar karena sebagian besar ibu tidak melakukan tindakan dengan benar. Semakin tinggi tingkat pendidikan seseorang maka semakin mudah untuk menerima informasi sehingga semakin layak pula pengetahuan yang dimiliki.

Perilaku yang didasari pengetahuan akan lebih langgeng daripada perilaku yang tidak didasari pengetahuan karena Pengetahuan atau kognitif merupakan domain yang sangat penting untuk terbentuknya perilaku seseorang

\section{SIMPULAN DAN SARAN}

\section{Simpulan}

Sebagian besar responden memiliki pengetahuan yang cukup tentang vulva hygiene di Klinik Utama Suko Asih Kabupaten Sukoharjo. Responden sebagian besar memiliki perilaku cukup dalam melakukan perawatan perineum di Klinik Utama Suko Asih Kabupaten Sukoharjo. Ada hubungan antara hubungan pengetahuan ibu nifas tentang vulva hygiene dengan perilaku perawatan perineum di Klinik Utama Suko Asih Kabupaten Sukoharjo

\section{Saran}

Ibu nifas diharapkan mampu meningkatkan pengetahuan tentang vulva hygiene baik dari majalah, televisi dan sosial media serta melakukan perawatan perineum dengan baik untuk mencegah adanya infeksi pada organ genetalia 


\section{DAFTAR PUSTAKA}

Azwar.s 2016. Sikap dan Perilaku, dalam sikap dan pengukurannya. Yogyakarta. Pustaka Pelajar

Dinas Kesehatan Provinsi Jawa Tengah. 2014. Profil Kesehatan Provinsi Jawa Tengah Tahun 2015. Dinas Kesehatan Jawa Tengah. Semarang.

2015. Profil Kesehatan Provinsi Jawa Tengah

Tahun 2015. Dinas Kesehatan

.I'anah, S dan M. Hartono. 2015. Hubungan Antara Pengetahuan Ibu Nifas Tentang Personal Hygiene Pada Luka Perineum Dengan Penyembuhan Luka Fase Proliferasi Di Wilayah Kerja Puskesmas Jenggot Kota Pekalongan Tahun 2013. Pena Jurnal Ilmu Pengetahuan Dan Teknologi 26(2): 157-170.

Maidatati (2016) Maidartati, dkk. Hubungan Pengetahuan dan Perilaku Vulva Hygiene Pada Saat Menstruasi remaja Putri. Jurnal Ilmu Keperawatan Vol. IV;2014

Profil Kesehatan Indonesia. 2014. Profil Kesehatan Indonesia Tahun 2015.Kementerian Kesehatan Republik Indonesia. Jakarta. 2015. Profil Kesehatan Indonesia Tahun 2015.Kementerian Kesehatan Republik Indonesia. Jakarta.

.Suryati, Y., E. Kusyati, dan W. Hastuti. 2013. Hubungan Tingkat Pengetahuan Ibu Nifas Tentang Perawatan Luka Perineum Dan Status Gizi Dengan Proses Penyembuhan Luka.Jurnal Manajemen Keperawatan1(1): 25-32.

Timbawa, S., R. Kundre, dan Y. Bataha. 2015. Hubungan Vulva Hygiene Dengan Pencegahan Infeksi Luka Perineum Pada Ibu Post Partum di Rumah Sakit Pancaran Kasih GMIM Manado. E-journal Keperawatan3(2).

Prety, V, D. Prety, T. R. K. Yolanda, B. 2017 Hubungan Perawatan Luka Perineum Dengan Perilaku Personal Hygiene Ibu Post Partum Di Rumah Sakit Pancaran Kasih Gmim Manado e-Journal Keperawatan (e-Kp) Volume 5 Nomor 1, Februari

Ratih. R.R (2018) Hubungan Pengetahuan Dan Sikap Ibu Nifas Tentang Perawatan Luka Perineum Di Rumah Bersalin Rossita Pekanbaru 2017 , Jurnal Kesmas Volume 1, No 1, Januari-Juni 2018

Verby Divini Prety Tulas Rina Kundre Yolanda Bataha (2017) , Hubungan Perawatan Luka Perineum Dengan Perilaku Personal Hygiene Ibu Post Partum Di Rumah Sakit Pancaran Kasih Gmim Manado, e-Journal Keperawatan (e-Kp) Volume 5 Nomor 1, Februari 2017 